\title{
Inflammatory Pain Upregulates Spinal Inhibition via Endogenous Neurosteroid Production
}

\author{
Pierrick Poisbeau, Christine Patte-Mensah, Anne Florence Keller, Michel Barrot, Jean-Didier Breton, \\ Oliva Erendira Luis-Delgado, Marie José Freund-Mercier, Ayikoe Guy Mensah-Nyagan, and Rémy Schlichter \\ Institut des Neurosciences Cellulaires et Intégratives, Centre National de la Recherche Scientifique/Université Louis Pasteur, F-67084 Strasbourg, France
}

\begin{abstract}
Inhibitory synaptic transmission in the dorsal horn $(\mathrm{DH})$ of the spinal cord plays an important role in the modulation of nociceptive messages because pharmacological blockade of spinal $\mathrm{GABA}_{\mathrm{A}}$ receptors leads to thermal and mechanical pain symptoms. Here, we show that during the development of thermal hyperalgesia and mechanical allodynia associated with inflammatory pain, synaptic inhibition mediated by $\mathrm{GABA}_{\mathrm{A}}$ receptors in lamina II of the $\mathrm{DH}$ was in fact markedly increased. This phenomenon was accompanied by an upregulation of the endogenous production of $5 \alpha$-reduced neurosteroids, which, at the spinal level, led to a prolongation of $\mathrm{GABA}_{\mathrm{A}}$ receptor-mediated synaptic currents and to the appearance of a mixed GABA/glycine cotransmission. This increased inhibition was correlated with a selective limitation of the inflammation-induced thermal hyperalgesia, whereas mechanical allodynia remained unaffected. Our results show that peripheral inflammation activates an endogenous neurosteroid-based antinociceptive control, which discriminates between thermal and mechanical hyperalgesia.
\end{abstract}

Key words: inflammatory pain; neurosteroid; $\mathrm{GABA}_{\mathrm{A}}$ receptors; synaptic currents; spinal cord; hyperalgesia

\section{Introduction}

A decrease in synaptic inhibition has been associated with various pathological situations, including epilepsy (Treiman, 2001; Jones-Davis and Macdonald, 2003) and pain (Millan, 1999; Woolf and Salter, 2000). In particular, fast synaptic inhibition mediated by $\mathrm{GABA}_{\mathrm{A}}$ receptors $\left(\mathrm{GABA}_{\mathrm{A}} \mathrm{Rs}\right)$ located on spinal cord lamina II (substantia gelatinosa) neurons plays a crucial role in the processing of peripheral nociceptive messages. Indeed, early hyperalgesia and allodynia are characteristic of both neuropathic and inflammatory pain, and are thought to be attributable in part to disinhibition in the spinal cord (Sivilotti and Woolf, 1994; Ishikawa et al., 2000; Harvey et al., 2004). Therefore, a promising therapeutic strategy might consist of facilitating the activity of endogenous modulatory systems, which control the synaptic inhibition mediated by $\mathrm{GABA}_{\mathrm{A}}$ Rs. Such systems may include anatomically identified supraspinal afferents (Millan, 2002) or local cellular networks involved in the production of paracrine or autocrine neuromodulators such as neurosteroids (Baulieu and Robel, 1990).

We recently showed that $3 \alpha, 5 \alpha$-reduced neurosteroids $(5 \alpha \mathrm{NS})$ exert a tonic control on $\mathrm{GABA}_{\mathrm{A}} \mathrm{R}$-mediated synaptic in-

\footnotetext{
Received May 16, 2005; revised 0ct. 26, 2005; accepted 0ct. 29, 2005.

This work was supported by the Centre National de la Recherche Scientifique/Université Louis Pasteur, Institut UPSA de la Douleur, Région Alsace, Fondation pour la Recherche Médicale, a grant from the Institut Universitaire de France to R.S., and research grants from the French Ministère de la Recherche (Action Concertée Incitative) (P.P., M.B.). A.F.K. and J.-D.B. were fellows of the Fondation pour la Recherche Médicale. 0.E.L.-D. is a fellow of Programa de Mejoramiento del Profesorado (PROMEP UAZAC-185). We thank Francine Herzog, Gregory Schott, and Claire Letissier for excellent technical assistance.

Correspondence should be addressed to Dr. Pierrick Poisbeau, Institut des Neurosciences Cellulaires et Intégratives, Centre National de la Recherche Scientifique/Université Louis Pasteur, 21 rue René Descartes, F-67084 Strasbourg, France. E-mail: poisbeau@neurochem.u-strasbg.fr.

DOI:10.1523/JNEUROSCI.3841-05.2005

Copyright $\odot 2005$ Society for Neuroscience $\quad 0270-6474 / 05 / 2511768-09 \$ 15.00 / 0$
}

hibition in lamina II of the spinal cord dorsal horn (DH) at early stages of postnatal development (Keller et al., 2004). This control progressively disappeared during the first 3 weeks of postnatal life, but pharmacological stimulation of neurosteroidogenesis remained possible in adult animals and enhanced synaptic inhibition to a level comparable with that observed at early developmental stages. In addition, the presence of the enzymes required for the synthesis of $5 \alpha$ NS has been documented in the spinal cord of the adult rat (Poletti et al., 1998; Patte-Mensah et al., 2003, 2004). Therefore, we hypothesized that the production of neurosteroids in the spinal cord might be reactivated in adult animals under particular physiological/pathological situations and could be involved in the control of incoming nociceptive messages. Because lamina II contains mostly interneurones, which play a key role in the integration/modulation of nociceptive messages, we decided to study the modulation of $\mathrm{GABA}_{\mathrm{A}}$ receptormediated synaptic inhibition in lamina II neurons by endogenously produced neurosteroids in an experimental model of inflammatory pain, and evaluated its consequences on thermal and mechanical pain thresholds.

\section{Materials and Methods}

Carrageenan inflammation. All experiments were performed on adult Wistar rats. Briefly, a single intraplantar injection $(100 \mu \mathrm{l})$ of $\lambda$-carrageenan [ $3 \%$ in $\mathrm{NaCl}(0.9 \%)$; Sigma, St. Louis, MO] was performed in the plantar surface of the right hindpaw for behavioral experiments, whereas bilateral injections (right and left) were done in the case of electrophysiological and biochemical studies. All experiments were conducted in conformity with the rules of the European Committee Council Direction of November 24, 1986 (86/609/EEC) and the French Department of Agriculture (License No. 67-116 to P. Poisbeau).

Preparation of spinal cord slices. As described previously (Keller et al., 2001, 2004), transverse slices of lumbar spinal cord were prepared from 
Table 1. GABA ${ }_{A} R$ mIPSCs are prolonged by allopregnanolone and THDOC

\begin{tabular}{llllrr}
\hline & Amp. (pA) & RT (ms) & $\tau D$ (ms) & Freq. (Hz) & $n$ \\
\hline Control & $31.3 \pm 3.1$ & $0.54 \pm 0.05$ & $16.4 \pm 0.8$ & $0.19 \pm 0.03$ & 16 \\
Diazepam & $34.4 \pm 2.1$ & $0.76 \pm 0.07^{*}$ & $28.7 \pm 1.1^{* *}$ & $0.21 \pm 0.03$ & 7 \\
Allopregnanolone & $29.5 \pm 5.5$ & $0.73 \pm 0.05^{*}$ & $32.6 \pm 2.6^{* *}$ & $0.20 \pm 0.05$ & 7 \\
THD0C & $28.7 \pm 1.0$ & $0.88 \pm 0.16^{*}$ & $30.5 \pm 1.7^{* *}$ & $0.21 \pm 0.08$ & 6 \\
PK-11195 & $27.4 \pm 2.6$ & $0.51 \pm 0.05$ & $20.5 \pm 0.9$ & $0.18 \pm 0.03$ & 18 \\
Finasteride & $33.0 \pm 5.7$ & $0.53 \pm 0.03$ & $17.7 \pm 1.2$ & $0.27 \pm 0.09$ & 6 \\
\hline
\end{tabular}

The table gives the main characteristics of GABA R mIPSCs: mean amplitude (Amp.), frequency of occurrence (Freq.), $10-90 \%$ RT, and monoexponential decay time constants $(\tau D)$. Perfusion of diazepam $(1 \mu \mathrm{M})$, allopregnanolone $(100 \mathrm{nM})$, or THDOC $(100 \mathrm{nM})$ significantly prolonged RT and $\tau D$ without affecting the amplitude and the frequency of occurrence of mIPSCs. PK11195 $(10 \mu \mathrm{M})$ and finasteride $(50 \mu \mathrm{m})$ were applied for at least $6 \mathrm{~h}$.

Asterisks indicate statistically significant differences at ${ }^{*} p<0.01$ and ${ }^{* *} p<0.001$ (Student's $t$ test).

adult Wistar rats (postnatal day $>30$ ) (Depré, St. Doulchard, France) deeply anesthetized with a mixture of ketamine $(75 \mathrm{mg} / \mathrm{kg}$, i.p.) and xylazine $(5 \mathrm{mg} / \mathrm{kg}$, i.p.). Animals were killed 3 or $18-24 \mathrm{~h}$ after carrageenan or saline injections, and the lumbar spinal cord was collected. Transverse slices $(250-300 \mu \mathrm{m})$ of the spinal cord were cut and incubated in a chamber filled with artificial CSF (ACSF) containing the following (in mM): $126 \mathrm{NaCl}, 26 \mathrm{NaHCO}_{3}, 2.5 \mathrm{KCl}, 1.25, \mathrm{NaH}_{2} \mathrm{PO}_{4}$, and 10 glucose, bubbled with $\left.95 \% \mathrm{O}_{2}, 5 \% \mathrm{CO}_{2}, \mathrm{pH} 7.35 \pm 0.05\right)$. In a set of experiments, finasteride (FIN) was used to inhibit neurosteroidogenesis in vivo. For this purpose, one group of rats was pretreated with finasteride (30 mg/kg; $20 \% \mathrm{v} / \mathrm{v}$ ethanol and olive oil, s.c.) $24 \mathrm{~h}$ before the carrageenan injections.

Electrophysiological recordings. Lamina II neurons were visualized using an infrared camera and recorded in the whole-cell configuration of the patch-clamp technique. The pipette was filled with a solution containing the following (in mM): $125 \mathrm{CsCl}, 2 \mathrm{MgCl}_{2}, 10 \mathrm{HEPES}, \mathrm{pH} 7.3$, adjusted with $\mathrm{CsOH}$. $\mathrm{GABA}_{\mathrm{A}} \mathrm{R}$-mediated miniature IPSCs (mIPSCs) were isolated by using an ACSF containing $0.5 \mu \mathrm{M}$ tetrodotoxin (Latoxan, Rosans, France), 2 mm kynurenic acid (Fluka, Neu-Ulm, Germany), and $1 \mu \mathrm{M}$ strychnine (Sigma). In some experiments, strychnine was omitted to record all miniature inhibitory synaptic currents. Data acquisition and analysis were performed as described previously (Keller et al., 2001, 2004). Mean values of amplitudes, $10-90 \%$ rise times, decay time constants, and frequency of occurrence of mIPSCs were compared between groups using Student's $t$ tests with a confidence interval set at 0.95 . The Kolmogorov-Smirnov test (KS test) was used to compare the cumulative distributions. Distributions were considered different when $p<0.01$. All results are given as mean \pm SEM.

Pulse-chase and HPLC-Flo/One characterization of neurosteroids. Conversion of the precursor $\left[{ }^{3} \mathrm{H}\right]$ pregnenolone $\left(\left[{ }^{3} \mathrm{H}\right] \mathrm{PREG}\right)$ into radioactive metabolites by lumbar spinal cord segments was studied using a previously validated approach that combines the pulse-chase technique, HPLC purification of tissue extracts, and continuous flow detection of newly synthesized ${ }^{3} \mathrm{H}$-neurosteroids (Patte-Mensah et al., 2003). The amount of radioactive neurosteroids synthesized from $\left[{ }^{3} \mathrm{H}\right] \mathrm{PREG}$ was expressed as a percentage of the total radioactivity contained in all peaks resolved by the HPLC-Flo/One system, including $\left[{ }^{3} \mathrm{H}\right] \mathrm{PREG}$ itself. Each value is the mean of four independent experiments. Student's $t$ test was used for comparison in pairs, whereas ANOVA followed by Bonferroni's test was applied for multiparameter analyses.

Behavioral testing. Finasteride ( $30 \mathrm{mg} / \mathrm{kg}$ in olive oil, s.c.) or olive oil (1 $\mathrm{ml} / \mathrm{kg}$, s.c.) was injected $24 \mathrm{~h}$ before unilateral intraplantar injection of carrageenan $[3 \%$ in $\mathrm{NaCl}(0.9 \%) ; 100 \mu \mathrm{l}]$ in the right hindpaw. The animals ( $n=8-11$ per group) were tested for a time-course response to thermal or mechanical stimulation. For this purpose, baseline responses before finasteride injection and before carrageenan injection, and withdrawal responses $1,3,5,7,12,24$, and $48 \mathrm{~h}$ after intraplantar injection were determined. The thermal response was tested using the Plantar test, or Hargreaves' method (Ugo Basile, Comerio, Italy), allowing us to differentiate the response of each paw (Hargreaves et al., 1988). The mechanical response was evaluated using digital calibrated forceps (Société Bioseb, Chaville, France). For both tests, three measures were taken at a given time point for each hindpaw. The averaged value was used for additional analysis. Both tests were performed consecutively within 20 $\mathrm{min}$, and followed by a measure of paw volume. At the $48 \mathrm{~h}$ time point, the finasteride-carrageenan group $(n=11)$ was separated into two subgroups, receiving either a second injection of finasteride $(n=5)$ or an injection of vehicle (olive oil; $n=6$ ). These animals were tested $24 \mathrm{~h}$ later for their responses to thermal and mechanical stimulation.

\section{Results \\ Properties of inhibitory synaptic transmission and its modulation by neurosteroids}

The properties of mIPSCs in lamina II of lumbar spinal cord slices has recently been extensively characterized (Chéry and De Koninck, 1999; Keller et al., 2001, 2004; Ahmadi et al., 2002). In the adult, lamina II neurons display only fast-decaying strychnine-sensitive glycine receptor (GlyR) mIPSCs and slow-decaying bicuculline-sensitive $\mathrm{GABA}_{\mathrm{A}} \mathrm{R}$ mIPSCs. Both types of mIPSCs possess monoexponential decay kinetics (for GABA $\mathrm{A}_{\mathrm{A}}$ mIPSCs values, see Table 1) but biexponentially decaying $\mathrm{GABA}_{\mathrm{A}} \mathrm{R}$ mIPSCs were never observed in our study or other studies on lamina II neurons (Chéry and De Koninck, 1999; Ahmadi et al., 2002). These results are in line with, but also slightly different from, those obtained on neurons from the trigeminal nucleus pars caudalis (Grudt and Henderson, 1998). In the latter case, the authors described two populations of $\mathrm{GABA}_{\mathrm{A}} \mathrm{R}$ mIPSCs. The small sized mIPSCs exhibited monoexponential decay kinetics and amplitudes comparable with those observed in our study. The second population of $\mathrm{GABA}_{\mathrm{A}} \mathrm{R}$ mIPSCs had larger amplitudes and biexponential decay kinetics. Although large amplitude $\mathrm{GABA}_{\mathrm{A}} \mathrm{R}$ mIPSCs have been recorded in adult lamina I-II neurons (Chéry and De Koninck, 1999), biexponentially decaying mIPSCs have not been observed in this structure. Differences between the two preparations might, therefore, be related to the specific expression of certain $\mathrm{GABA}_{\mathrm{A}} \mathrm{R}$ subunits in the trigeminal nucleus (Araki and Tohyama, 1992; Kondo et al., 1994) that are not found in lamina II of the lumbar spinal cord (Bohlhalter et al., 1996).

Most $\mathrm{GABA}_{\mathrm{A}} \mathrm{Rs}$ expressed in the CNS are positively modulated by $5 \alpha \mathrm{NS}$ (Lambert et al., 2003), such as allopregnanolone [5 $\alpha$-pregnan-3 $\alpha$-ol-20-one (AP)] or tetrahydrodeoxycorticosterone [5 $\alpha$-pregnan-3 $\alpha, 21$-diol-20-one (THDOC)] (Fig. 1A). However, their sensitivity to neurosteroids is highly variable as a function of developmental stage (Poisbeau et al., 1997; Cooper et al., 1999), physiological (Smith et al., 1998; Koksma et al., 2003) or pathological (Mtchedlishvili et al., 2001; Leroy et al., 2004) states, as well as subunit composition, or degree of phosphorylation of the receptors (Brussaard and Koksma, 2003; Lambert et al., 2003). Thus, we first verified the sensitivity of synaptic $\mathrm{GABA}_{\mathrm{A}}$ Rs expressed in lamina II neurons to THDOC and AP (Fig. $1 B, C$; Table 1 ).

Perfusion of THDOC (100 nM) and AP (100 nM) increased the monoexponential decay time constant $(\tau)$ of pharmacologically isolated $\mathrm{GABA}_{\mathrm{A}} \mathrm{R}$ mIPSCs by $80 \%$ (from $\tau=17.0 \pm 1.1 \mathrm{~ms}$ to $\tau=$ $30.5 \pm 1.7 \mathrm{~ms} ; n=6 ; p<0.05$; Student's $t$ test) and $83 \%$ (from $\tau=17.9 \pm 1.2 \mathrm{~ms}$ to $\tau=32.6 \pm 2.6 \mathrm{~ms} ; n=7 ; p<0.05$; Student's $t$ test), respectively. Application of THDOC or AP also increased the $10-90 \%$ rise time (Table 1 ) without affecting the mean amplitude and frequency of occurrence of $\mathrm{GABA}_{\mathrm{A}} \mathrm{R}$-mediated mIPSCs. Similar effects were also observed during the application of the benzodiazepine diazepam (DZP; $1 \mu \mathrm{M}$ ) (Table 1). This result indicated that in the adult, synaptic $\mathrm{GABA}_{\mathrm{A}}$ Rs mediating 
A

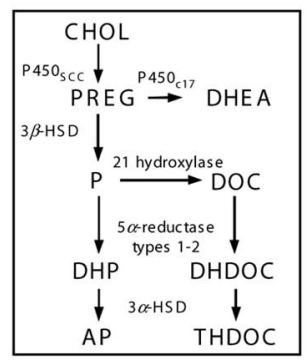

C

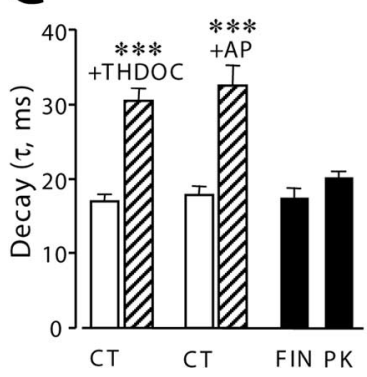

B

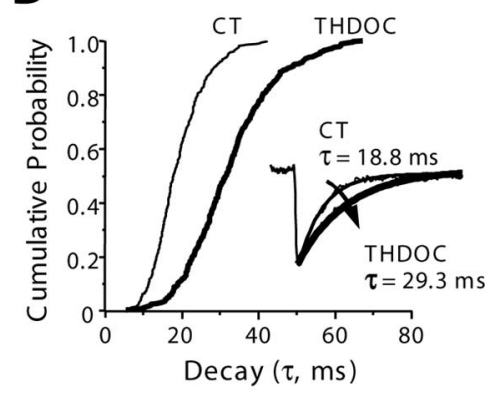

$\mathrm{D}$

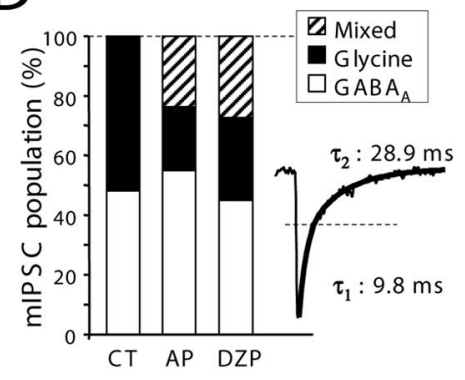

Figure 1. $A P$ and $T H D O C$ prolong $G A B A_{A}$ receptor-mediated $m I P S C S$ and trigger the reappearance of mixed $G A B A_{A} R / G l y R$ mIPSCs. $A$, Schematic representation of the biosynthetic steps leading to the production of $A P$ and THDOC, two $5 \alpha \mathrm{NS}$, which are potent positive allosteric

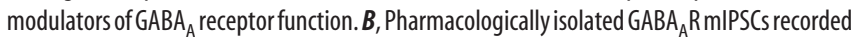
in lamina Il of adult rat lumbar spinal cord slices were prolonged in duration by superfusion with THDOC (100 nm). The graph illustrates the cumulative probability distribution of the monoexponential decay time constants ( $\tau$; in milliseconds) obtained by fitting the decaying phase of $\mathrm{GABA}_{\mathrm{A}} \mathrm{R}$ mIPSCs in a single neuron before (thin line) and after (thick line) a long (>20 min) application of THDOC. THDOC prolonged the duration of all GABA $R$ mIPSCS (inset, representative current trace) and shifted the cumulative distribution of the decay time constants to the higher values ( $\mathrm{KS}$ test; $p<0.001$ ). $C$, Histogram summarizing the results obtained with THDOC $(n=7)$ and $\mathrm{AP}(n=7)$. Note that, under basal conditions, inhibition of neurosteroidogenesis by FIN ( $50 \mu \mathrm{m} ; n=6)$, a potent inhibitor of $5 \alpha \mathrm{R} 2$, did not modify the decay time constant of $\mathrm{GABA}_{A} \mathrm{R}$ mIPSCs in adult lamina II neurons. A similar result was obtained with PK11195 (10 $\mu \mathrm{M}$; $n=18$ ), an inhibitor of the PBR, which stimulates cholesterol transport into the mitochondria and initiates neurosteroidogenesis. $\boldsymbol{D}$, Histogram representing the proportion of GlyR-only,

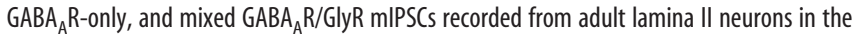
control condition and in the presence of AP (100 nm; $n=7)$ or DZP $(1 \mu \mathrm{m} ; n=6)$. Mixed

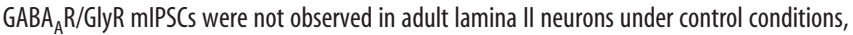
although they were detected in the presence of THDOC or DZP because of the conversion of a fraction of glycinergic mIPSCs to mixed $G_{A B A} R / G l y R$ mIPSCs. A representative example of a mixed mIPSC is shown in the inset. The fast and slow component contributed equally to the total mixed mIPSC amplitude (inset, dotted line). Results are expressed as mean value \pm SEM. ***Statistical significance at $p<0.001$.

inhibitory transmission in lamina II were highly sensitive to $5 \alpha$ NS.

To check for the existence of a basal modulation of synaptic $\mathrm{GABA}_{\mathrm{A}}$ Rs by endogenous $5 \alpha \mathrm{NS}$, we incubated the slices with FIN, a blocker of $5 \alpha$ reductase (Stoner, 1990), or with 1-(2chlorophenyl)- $N$-methyl- $N$-(1-methylpropyl)-3-isoquinoline carboxamide (PK11195), an antagonist of the mitochondrial peripheral benzodiazepine receptor (PBR), which controls the initiation of neurosteroidogenesis (Casellas et al., 2002). The decay time constants of GABA $\mathrm{A}_{\mathrm{A}}$ mIPSCs were similar in control $(\tau=$ $16.4 \pm 0.8 \mathrm{~ms} ; n=16)$ and in FIN-treated ( $50 \mu \mathrm{M}$ for $>6 \mathrm{~h} ; \tau=$ $17.7 \pm 1.2 \mathrm{~ms} ; n=6)$ or PK11195-treated spinal cord slices (10 $\mu \mathrm{M}$ for $>6 \mathrm{~h} ; \tau=20.5 \pm 0.9 \mathrm{~ms} ; n=18$ ) (Fig. $1 C$, Table 1 ), indicating that, under basal physiologic conditions, the levels of $5 \alpha \mathrm{NS}$ achieved in the adult spinal cord slices were not sufficient to significantly affect the kinetic properties of synaptic $G_{A B A} R s$ in lamina II.

Recording the total population of fast mIPSCs in the absence of strychnine indicated that GlyR and $\mathrm{GABA}_{\mathrm{A}} \mathrm{R}$ mIPSCs were equally represented in adult lamina II neurons with proportions of $51.7 \pm 6.1$ and $48.3 \pm 6.1 \%(n=12)$, respectively (Fig. $1 D)$. This was in good agreement with our previous observation concerning the maturation of inhibitory synaptic transmission in lamina II (Keller et al., 2001, 2004). Interestingly, superfusion with AP $(100 \mathrm{nM})$ induced a prolongation of $\mathrm{GABA}_{\mathrm{A}} \mathrm{R}$ currents and led to the appearance of mixed $\mathrm{GABA}_{\mathrm{A}} \mathrm{R} / \mathrm{GlyR}$ mIPSCs $(23.5 \pm 5.7 \% ; n=7)$. These mixed events had biexponential decay phases with a fast component having the kinetic and pharmacological properties of GlyR mIPSCs $(\tau=7.4 \pm 2.0 \mathrm{~ms} ; n=7)$ and a slow component resembling AP-prolonged $\mathrm{GABA}_{\mathrm{A}} \mathrm{R}$ $\operatorname{mIPSCs}(\tau=32.2 \pm 2.7 \mathrm{~ms} ; n=7)$. Because the overall frequency of mIPSCs as well as that of "pure" slowly and monoexponentially decaying $\mathrm{GABA}_{\mathrm{A}} \mathrm{R}$ mIPSCs were unchanged during the superfusion with AP or THDOC, it follows that the appearance of mixed mIPSCs was caused by the unmasking of a GABA Current $_{A}$ component in a subset of GlyR mIPSCs (Fig. $1 D$ ). Therefore, our results suggest that, in the adult, $5 \alpha \mathrm{NS}$ increase the fast inhibitory synaptic transmission in the interneurone network of lamina II by prolonging $\mathrm{GABA}_{\mathrm{A}} \mathrm{R}$ mIPSCs and by inducing the reappearance of mixed $\mathrm{GABA}_{\mathrm{A}} \mathrm{R} / \mathrm{GlyR}$ mIPSCs.

\section{Synthesis of neurosteroids in adult spinal cord slices}

All of the enzymes necessary for the synthesis of endogenous $5 \alpha \mathrm{NS}$ are present in lamina II of the rat spinal cord (Coirini et al., 2002; Patte-Mensah et al., 2003, 2004). Biosynthesis of THDOC and AP from cholesterol or PREG requires an obligatory step involving $5 \alpha$-reductases (Fig. $1 A$ ), which exist under two isoforms termed type $1(5 \alpha \mathrm{R} 1)$ and type $2(5 \alpha \mathrm{R} 2)$. Using an immunohistochemical approach, we recently showed that immunoreactivity for $5 \alpha \mathrm{R} 1$ was very low in the spinal cord, whereas a strong $5 \alpha \mathrm{R} 2$ immunostaining was detected in laminas I-II (PatteMensah et al., 2004).

To assess the functionality of the biosynthetic enzymes in the spinal cord, we performed pulse-chase experiments on lumbar spinal cord slices and studied the conversion of exogenously provided $\left[{ }^{3} \mathrm{H}\right] \mathrm{PREG}$ into radioactive neurosteroids. Our results demonstrate the neosynthesis of neurosteroids having the same characteristics as AP and THDOC (Fig. 2A). The conversion of $\left[{ }^{3} \mathrm{H}\right] \mathrm{PREG}$ to $\left[{ }^{3} \mathrm{H}\right] \mathrm{AP}$ and to $\left[{ }^{3} \mathrm{H}\right] \mathrm{THDOC}$ was significantly reduced when slices were incubated with finasteride (Fig. 2 B). Moreover, when the activity of $5 \alpha \mathrm{R} 2$ was blocked with finasteride, we observed an accumulation of newly synthesized $\left[{ }^{3} \mathrm{H}\right]$ progesterone $\left(\left[{ }^{3} \mathrm{H}\right] \mathrm{P}\right)$ and $\left[{ }^{3} \mathrm{H}\right]$ deoxycorticosterone $\left(\left[{ }^{3} \mathrm{H}\right] \mathrm{DOC}\right)$, which serve as precursors for $\left[{ }^{3} \mathrm{H}\right] \mathrm{AP}$ and $\left[{ }^{3} \mathrm{H}\right] \mathrm{THDOC}$, respectively (Fig. $2 \mathrm{~B}$ ). It must also be noted that our results provide the first demonstration of the synthesis of THDOC from pregnenolone in the CNS, suggesting that, at least in the spinal cord, THDOC might be a neurosteroid with important physiological functions.

\section{Effect of peripheral inflammation on inhibitory} synaptic transmission

To determine whether the metabolism and action of endogenous $5 \alpha$ NS were likely to change after the induction of an inflammatory pain state, we used the well established model of carrageenan-induced inflammation (Vinegar et al., 1987). $\mathrm{GABA}_{\mathrm{A}} \mathrm{R}$ mIPSCs recorded from inflamed animals $24 \mathrm{~h}$ after the subcutaneous injection of carrageenan into the hindpaws had significantly longer decay time constants $(\tau=34.1 \pm 1.9 \mathrm{~ms} ; n=$ 22) than those of saline-injected controls $(\tau=19.5 \pm 0.7 \mathrm{~m} ; n=$ $14 ; p<0.001$; Student's $t$ test) (Fig. $3 A, C$ ). No differences were 

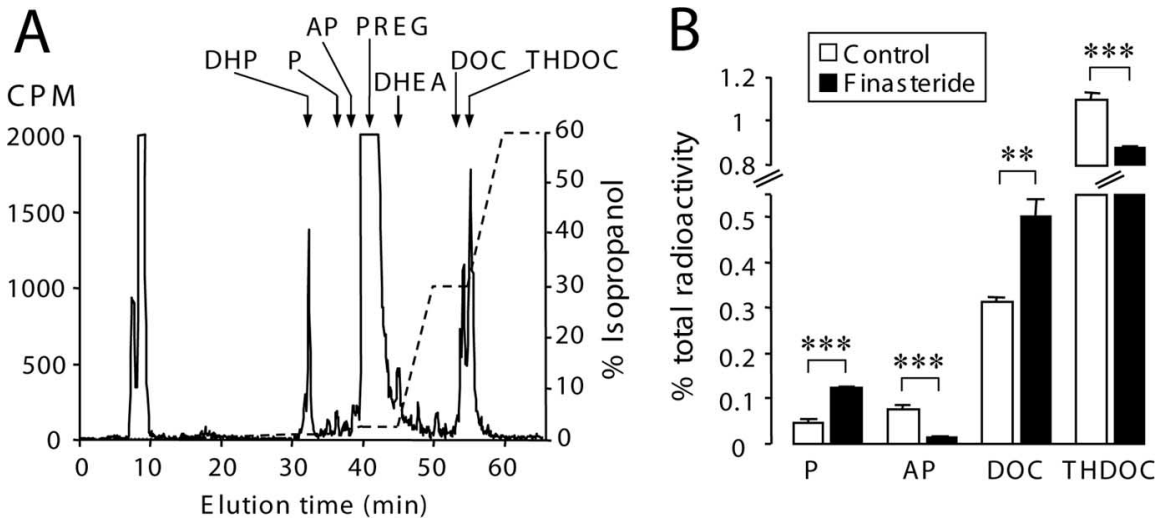

Figure 2. AP and THDOC are synthesized in the adult spinal cord. A, Analysis of radioactive neurosteroids present in the extracellular medium after a $3 \mathrm{~h}$ incubation of adult rat spinal cord slices with [ ${ }^{3} \mathrm{H}$ ]PREG. The ordinate indicates the radioactivity measured in the HPLC eluent. The dashed line represents the gradient of secondary solvent (percentage of isopropanol). The arrows indicate the positions of standard steroids (for abbreviations, see below). $\boldsymbol{B}$, In spinal cord slices of adult control rats, a basal production of pregnenolone-derived neurosteroids, which included AP and THDOC, was detected. Inhibition of $5 \alpha$ R2 with finasteride (50 $\mu \mathrm{m}$; black bars) reduced the amount of newly synthesized THDOC and AP and resulted in the accumulation of their respective precursors, DOC and P. Results are expressed as mean value \pm SEM. Asterisks indicate statistical significance at ${ }^{* *} p<0.01$ or ${ }^{* * *} p<0.001$. CHOL, Cholesterol; PREG, pregnenolone; DHEA, dehydroepiandrosterone; P, progesterone; DOC, deoxycorticosterone; DHDOC, dihydrodeoxycorticosterone; DHP, dihydroprogesterone; AP, allopregnanolone; THDOC, tetrahydrodeoxycorticosterone.

noted in the mean frequency of occurrence or amplitude of $\mathrm{GABA}_{\mathrm{A}} \mathrm{R}$ mIPSCs (Table 2). However, GABA $\mathrm{A}$ mIPSCs of carrageenan-injected animals displayed an increase in 10-90\% rise time values [saline, rise time $(\mathrm{RT})=0.521 \pm 0.042 \mathrm{~ms}, n=$ 14 ; carrageenan, $24 \mathrm{~h}, \mathrm{RT}=0.936 \pm 0.086 \mathrm{~ms}, n=22 ; p<0.001$; Student's $t$ test]. In experiments allowing the detection of both GlyR and $\mathrm{GABA}_{\mathrm{A}} \mathrm{R}$ mIPSCs, we noted a reduction in the proportion of GlyR mIPSCs (saline, $48.8 \pm 3.3 \%, n=10$; carrageenan, $24 \mathrm{~h}, 26.2 \pm 2.9 \%, n=18)$ and the reappearance of mixed GABA $_{\mathrm{A}} \mathrm{R} /$ GlyR mIPSCs $(20.6 \pm 2.4 \% ; n=18)$ in all neurons from which we recorded (Fig. $3 B$ ). These biexponentially decaying mIPSCs totally disappeared after application of either bicuculline $(n=5)$ or strychnine $(n=12)$, indicating that they were mixed GABA ${ }_{\mathrm{A}}$ R/GlyR mIPSCs (Keller et al., 2001, 2004). Interestingly, the effect of carrageenan injection on $\mathrm{GABA}_{\mathrm{A}} \mathrm{R}$ current kinetics and mixed mIPSCs was observed as early as $3 \mathrm{~h}$ after the injection of carrageenan (Table 2) and was very similar to that obtained after exogenous application of AP to spinal cord slices from naive animals (see above) (Fig. $1 B-D$ ).

These results suggested that the prolongation of $G_{A B A} R$ mIPSCs and the reappearance of mixed GABA $\mathrm{A}_{\mathrm{A}} / \mathrm{GlyR}$ mIPSCs might eventually be attributable to the stimulation of the synthesis of $5 \alpha \mathrm{NS}$ by carrageenan-induced inflammation. To test this hypothesis, we decided to incubate spinal cord slices with finasteride or PK11195 and to check whether these treatments would suppress the inflammation-induced prolongation of $\mathrm{GABA}_{\mathrm{A}} \mathrm{R}$ mIPSCs. However, before starting these experiments, we carefully checked that incubation of the slices in physiological saline for several hours would not, per se, change the kinetics of the mIPSCs.

As illustrated in Figure 3C (left graph), the decay kinetics of $\mathrm{GABA}_{\mathrm{A}} \mathrm{R}$ mIPSCs from carrageenan-injected (incubation 1-4 h, $\tau=35.0 \pm 2.7 \mathrm{~ms}, n=11$; incubation $5-8 \mathrm{~h}, \tau=33.1 \pm 2.9 \mathrm{~ms}$, $n=11$ ) as well as from saline-injected animals (incubation $1-4 \mathrm{~h}, \tau=35.0 \pm 2.7 \mathrm{~ms}, n=11$; incubation $5-8 \mathrm{~h}, \tau=33.1 \pm$ $2.9 \mathrm{~ms}, n=11$ ) remained stable for at least $8 \mathrm{~h}$ of incubation. When under the same conditions slices were incubated in the presence of FIN $(50 \mu \mathrm{M})$ or PK11195 $(10 \mu \mathrm{M})$, the duration of $\mathrm{GABA}_{\mathrm{A}} \mathrm{R}$ mIPSCs decreased over time for carrageenan-injected animals (Fig. 3C, right graph). Interestingly, there was no significant change in mIPSC duration over the first $4 \mathrm{~h}$ of incubation (FIN, $\tau=30.0 \pm 2.6 \mathrm{~ms}, n=5$; PK11195, $\tau=32.8 \pm 1.6 \mathrm{~ms}, n=3)$. However, the decay time constant value of $\mathrm{GABA}_{\mathrm{A}} \mathrm{R}$ mIPSCs after $5-8 \mathrm{~h}$ in the presence of FIN ( $\tau=18.6 \pm 1.0 \mathrm{~ms} ; n=9$ ) or PK11195 $(\tau=22.1 \pm 1.2 \mathrm{~ms} ; n=11)$ reached a value comparable with that of saline-injected animals (Fig. 3C, Table 2).

These results indicated that the effect of peripheral inflammation on the kinetics of $\mathrm{GABA}_{\mathrm{A}} \mathrm{R}$ mIPSCs involved a stimulation of the local synthesis of $5 \alpha \mathrm{NS}$ in the dorsal horn of the spinal cord. In line with this hypothesis, the amounts of $\left[{ }^{3} \mathrm{H}\right] \mathrm{AP}$ and $\left[{ }^{3} \mathrm{H}\right]$ THDOC newly synthesized from $\left[{ }^{3} \mathrm{H}\right] \mathrm{PREG}$ in the spinal cord of carrageenan-injected rats were, respectively, $75 \pm 3$ and $35.2 \pm 1.2 \%(n=4)$ higher than in controls (Fig. 4). Furthermore, FIN $(50 \mu \mathrm{M})$ completely blocked the carrageenan-induced stimulation of AP and THDOC production in the spinal cord (Fig. 4).

\section{Role of endogenous $5 \alpha$ NS in the modulation of mechanical and thermal nociception}

Two important characteristics of inflammatory pain are the presence of a primary heat hyperalgesia and a mechanical allodynia. We therefore evaluated the consequences of the upregulation of $5 \alpha$ NS production and GABAergic transmission by peripheral inflammation on nociceptive thresholds to mechanical or heat stimuli. In these experiments, we compared the effect of pretreatment with finasteride $(30 \mathrm{mg} / \mathrm{kg}$, s.c.) on nociceptive thresholds of rats receiving either a saline (Fig. 5) or a carrageenan injection in the right hindpaw (Fig. 6).

In saline-injected rats, FIN had no influence on nociceptive responses triggered by either mechanical (calibrated pressure using forceps) (Fig. 5A) or heat (Hargreaves' test) (Fig. 5B) stimuli. This suggested that under basal conditions, $5 \alpha$ NS did not play a major role in the control of acute nociceptive mechanical or heat thresholds.

In rats injected with carrageenan, we observed a pronounced increase in mechanical (Fig. 6A) and thermal heat sensitivities (Fig. 6B). Finasteride had no effect on responses to mechanical stimuli (calibrated forceps) (Fig. 6A) but significantly reduced the threshold of nociceptive heat responses in the Hargreaves' test (Fig. $6 B)\left(F_{(6,210)}=2.43 ; p<0.03\right)$. These results indicated that blockade of the production of $5 \alpha$ NS significantly and selectively increased thermal heat hyperalgesia. The volume of the paw edema was not affected by finasteride (data not shown). Detailed analysis of the time course of heat hyperalgesia (Hargreaves' test) revealed a higher sensitivity to thermal stimuli in carrageenan animals pretreated with finasteride [finasteride/carrageenan ( $\mathrm{F} /$ C)], with respect to carrageenan animals pretreated with vehicle [oil/carrageenan $(\mathrm{O} / \mathrm{C})]$. This difference was detected as soon as $3 \mathrm{~h}$ after carrageenan injection and persisted for at least $24 \mathrm{~h}$. Moreover, the recovery to baseline nociceptive heat thresholds was delayed in $\mathrm{F} / \mathrm{C}$ animals compared with that of the $\mathrm{O} / \mathrm{C}$ group.

In these experiments, FIN was administered by a single subcutaneous injection and the recovery of thermal heat sensitivity to normal preinflammatory levels in the FIN group could be 

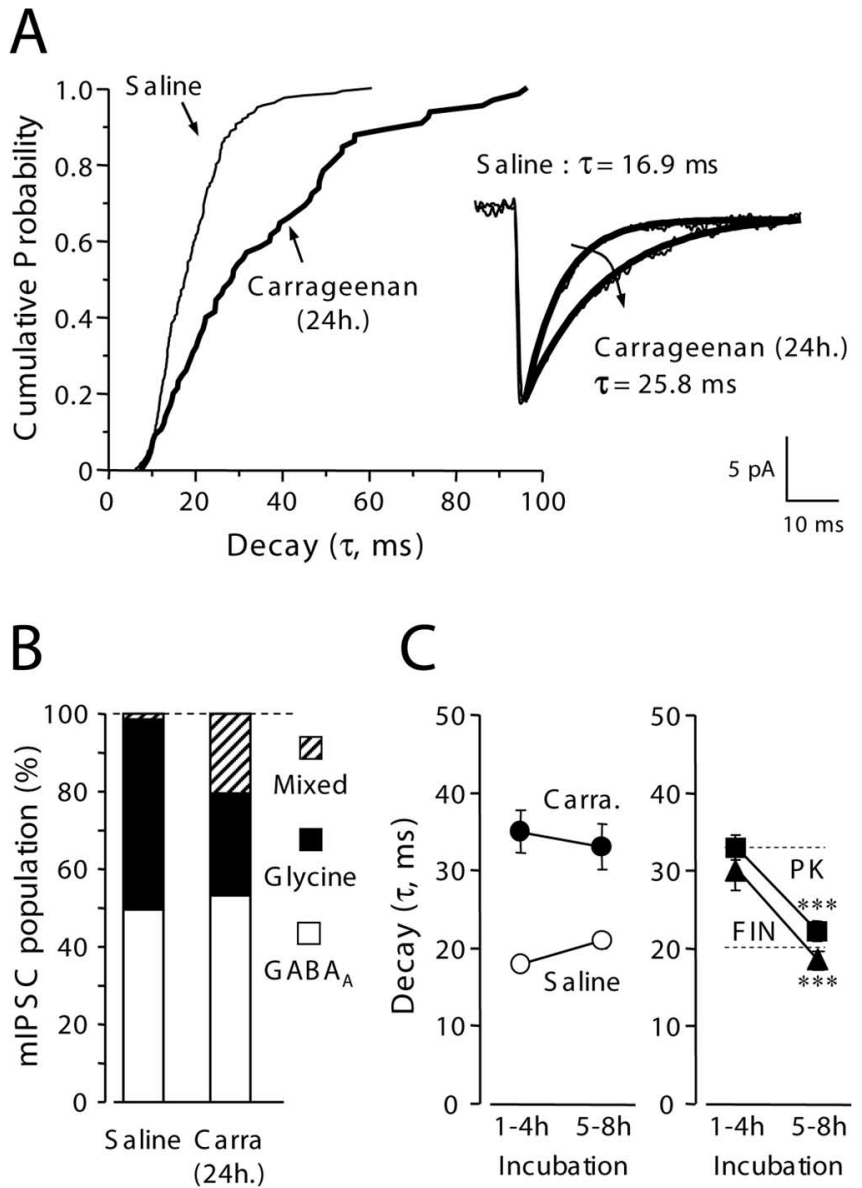

Figure 3. Peripheral inflammation upregulates the duration of $G A B A_{A} R$ mIPSCs and converts a fraction of GlyR mIPSCs to mixed GABA $A_{A} R / G l y R$ mIPSCs. A, Compared with saline conditions, GABA $A_{A} R$ mIPSCs in lamina II neurons of carrageenan-injected animals ( $24 \mathrm{~h}$ after injection) had longer decay time constants (right traces). This is clearly shown in the left graph comparing the distribution of the decay time constants in two different lamina II neurons recorded from saline-injected (thin line) and carrageenan-injected (thick line) animals (KS test;

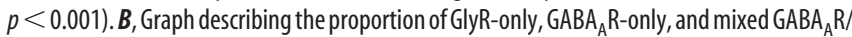
GlyR mIPSCs in adult lamina II neurons of saline- and carrageenan-injected rats. Mixed $G A B A_{A} R /$ GlyR mIPSCs were relatively abundant ( $\sim 20 \%) 24 \mathrm{~h}$ after the injection of carrageenan (Carra; $24 \mathrm{~h})$, whereas they were extremely rare in saline-injected animals $(1.4 \pm 0.6 \% ; n=10)$. Note that the proportion of $\mathrm{GABA}_{A} \mathrm{R}$ mIPSCs was the same in saline and carrageenan-injected animals, whereas a subpopulation of GlyR mIPSCS was converted into mixed $G A B A_{A} R / G l y R$ mIPSCs. C, Graphs representing the mean values ( $\pm S E M$ ) of the decay time constants of GABA $R$ R mIPSCS recorded in lamina II neurons from spinal cord slices of carrageenan-injected (black symbols) or saline-injected animals (white symbols) as a function of time of incubation. Incubation periods of $1-4$ and $5-8 \mathrm{~h}$ are represented in each case. Decay time constants of $G A B A_{A} R$ mIPSCs from carrageenan-injected animals were significantly larger than those from saline-injected animals (left graph). Note that for each animal group, decay time constant values remained similar and stable over time (up to $8 \mathrm{~h}$ ). In carrageenan-injected animals, incubation of spinal cord slices with either FIN (50 $\mu \mathrm{m}$; black triangles) or PK11195 (PK; $10 \mu \mathrm{m}$; black squares) induced an acceleration of the decay time constant, which was dependent on the duration of incubation (right graph). This phenomenon was observed only in the case of spinal cord slices incubated for $>5 \mathrm{~h}$ in the presence of FIN $(n=9)$ or PK $(n=11)$. The stippled lines indicate the values of the decay time constants observed for the carrageenan (top) and saline (bottom) groups after a $5-8 \mathrm{~h}$ incubation in normal ACSF (left graph). ${ }^{* * *}$ Statistical significance at $p<0.001$ (Student's $t$ test).

attributable to the unavailability of FIN, which could have been metabolized. To check this point, we used the test group having received an initial injection of FIN $24 \mathrm{~h}$ before carrageenan and reinjected the animals with either FIN $(n=5)$ or oil (vehicle; $n=$ 6) $48 \mathrm{~h}$ after the induction of the inflammation (Fig. 6C). When examining the thermal heat sensitivity of these animals $24 \mathrm{~h}$ later, we noticed that those reinjected with oil had recovered to a level comparable with that measured before inflammation, whereas in animals that were reinjected with FIN, the recovery to normal heat sensitivity was blocked. These results indicated that the effect of a single FIN injection was transient and that the recovery of FIN-injected animals observed in Figure $6 B$ was, in fact, caused by a time-dependent loss of the FIN-mediated blockade of the synthesis of $5 \alpha \mathrm{NS}$. In line with this hypothesis, a single reinjection of FIN was sufficient to prevent recovery toward normal heat sensitivity thresholds.

\section{Discussion}

Our results indicate that peripheral inflammation induced by intraplantar injection of carrageenan in the hindpaw led to an increase in inhibitory synaptic transmission within lamina II of the $\mathrm{DH}$ of the spinal cord. This phenomenon involved the upregulation of the local synthesis of $5 \alpha \mathrm{NS}$, which are potent positive allosteric modulators of $\mathrm{GABA}_{\mathrm{A}}$ receptors and occurred in parallel with a reduction of thermal heat but not of mechanical hyperalgesia associated with inflammatory pain.

Peripheral inflammation triggered an increase in the rise time and decay time constants of $\mathrm{GABA}_{\mathrm{A}} \mathrm{R}$ mIPSCs and the reappearance of mixed $\mathrm{GABA}_{\mathrm{A}} \mathrm{R} / \mathrm{GlyR}$ mIPSCs. These changes were blocked by FIN and PK11195, which inhibit the production of $5 \alpha \mathrm{NS}$ and were mimicked by exogenous application of AP or THDOC to spinal cord slices from naive rats. Diazepam, another positive allosteric modulator of $\mathrm{GABA}_{\mathrm{A}} \mathrm{R}$ function, also induced a similar effect on $\mathrm{GABA}_{\mathrm{A}} \mathrm{R}$ mIPSCs, suggesting that the changes in mIPSC kinetics observed after peripheral inflammation were a consequence of an increase in affinity of $\mathrm{GABA}_{\mathrm{A}}$ Rs. Positive allosteric modulators are known to prolong the decay kinetics of $\mathrm{GABA}_{\mathrm{A}} \mathrm{R}$ mIPSCs (Cherubini and Conti, 2001; Lambert et al., 2003) but have rarely been reported to increase the rise time of mIPSCs (Leroy et al., 2004). However, Chéry and De Koninck (1999) have elegantly demonstrated that in lamina I of adult rat spinal cord slices, application of the benzodiazepine flunitrazepam added a $\mathrm{GABA}_{\mathrm{A}} \mathrm{R}$ component to a majority of GlyR mIPSCs and that this component had slow rise time and decay time constants. This phenomenon was caused by the recruitment of extrasynaptic $\mathrm{GABA}_{\mathrm{A}}$ Rs via an increase in their affinity for GABA after flunitrazepam application. Our results are in line and totally consistent with these findings except that in our case the increase in affinity of $\mathrm{GABA}_{\mathrm{A}}$ Rs was mediated by $5 \alpha \mathrm{NS}$, the production of which was upregulated by peripheral inflammation. Although $\sim 20 \%$ of GlyR mIPSCs were transformed into mixed $\mathrm{GABA}_{\mathrm{A}} \mathrm{R} / \mathrm{GlyR}$ mIPSCs, we never detected a significant increase in the frequency of occurrence of pharmacologically isolated $\mathrm{GABA}_{\mathrm{A}} \mathrm{R}$ mIPSCs after blockade of GlyRs. This might be attributable to the fact that the $\mathrm{GABA}_{\mathrm{A}} \mathrm{R}$ component of mixed mIPSCs was relatively small in amplitude. Indeed, this component contributes $<33 \%$ to mixed mIPSCs in lamina II neurons (Keller et al., 2001) (i.e., $<10 \mathrm{pA}$ for an mIPSC of $30 \mathrm{pA}$ ) and, according to the results of Chéry and De Koninck (1999), the RTs are 10 times slower than that of GlyR mIPSCs or $\mathrm{GABA}_{\mathrm{A}} \mathrm{R}$ mIPSCs. Therefore, in the absence of the fast-rising phase associated with the activation of synaptic GlyR-mediated component, these small and slowly rising events might not have been detected as mIPSCs.

All enzymes necessary for the production of AP or THDOC are expressed by either glial cells or neurons in lamina II (PatteMensah et al., 2003, 2004), and our pulse-chase experiments demonstrated that significant amounts of AP and THDOC were detected in the supernatant of spinal cord slices from adult rats. In contrast to immature rats (Keller et al., 2004), the amounts of 
Table 2. Effect of finasteride and PK11195 on the main characteristics of $\mathrm{GABA}_{A} \mathrm{R}$ mIPSCs recorded in lamina II neurons from saline- and carrageenan-injected animals

\begin{tabular}{lllrr}
\hline & Amp. (pA) & RT (ms) & $\tau D(\mathrm{~ms})$ & Freq. (Hz) \\
\hline Saline & $29.9 \pm 2.5$ & $0.52 \pm 0.04$ & $19.5 \pm 0.7$ & $0.19 \pm 0.04$ \\
Carrageenan (3h) & $29.6 \pm 2.9$ & $0.90 \pm 0.21^{*}$ & $35.2 \pm 3.4^{*}$ & $0.15 \pm 0.05$ \\
Carrageenan (18-24h) & $29.2 \pm 1.7$ & $0.94 \pm 0.09^{*}$ & $34.1 \pm 1.9^{*}$ & 6 \\
Finasteride in vitro, $50 \mu \mathrm{M}$ & $33.0 \pm 5.7$ & $0.53 \pm 0.03$ & $17.7 \pm 1.2$ & $0.17 \pm 0.04$ \\
Finasteride i vivo, $30 \mathrm{mg} / \mathrm{kg}$ & $29.2 \pm 4.2$ & $0.62 \pm 0.09$ & $20.2 \pm 1.3$ & $0.19 \pm 0.04$ \\
PK11195, $10 \mu \mathrm{M}$ & $27.2 \pm 2.0$ & $0.51 \pm 0.06$ & $19.4 \pm 0.8$ & $0.13 \pm 0.05$ \\
\hline
\end{tabular}

Inhibition of neurosteroidogenesis was performed in vivo by pretreating animals with finasteride ( $30 \mathrm{mg} / \mathrm{kg}) 24 \mathrm{~h}$ prior to carrageenan injection. In vitro, spinal cord slices of carrageenan-injected animals were incubated for at least $6 \mathrm{~h}$ using either the $5 \alpha$-reductase inhibitor finasteride $(50 \mu \mathrm{M})$ or PK11195 $(10 \mu \mathrm{M})$, an antagonist of the PBR. Amp., Mean amplitude; Freq., frequency of occurrence; $\tau D$, monoexponential decay time constants.

Asterisks indicate statistically significant differences at $p<0.001$ (Student's $t$ test).

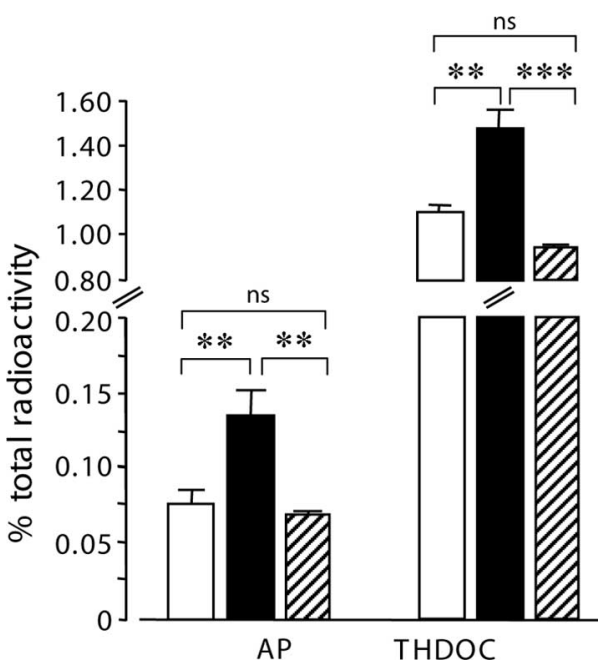

Figure 4. Peripheral inflammation is associated with an increased production of AP and THDOC in the spinal cord. The production of AP and THDOC was significantly increased in carrageenan-treated animals (black bars) compared with control (i.e., saline conditions; white bars). In the presence of FIN $(50 \mu \mathrm{m})$, the carrageenan-induced stimulation of AP and THDOC formation was completely blocked (hatched bars). Results are expressed as mean value \pm SEM. Asterisks indicate statistical significance at ${ }^{* *} p<0.01$ or ${ }^{* *} p<0.001$ (Student's $t$ test). ns, Statistically nonsignificant difference.

AP and/or THDOC produced under basal conditions in the vicinity of synaptic receptors were not sufficient to tonically influence the kinetics of $\mathrm{GABA}_{\mathrm{A}} \mathrm{R}$ mIPSCs. However, this production of $5 \alpha \mathrm{NS}$ was markedly increased close to synaptic sites after peripheral inflammation, leading to a prolongation of $\mathrm{GABA}_{\mathrm{A}} \mathrm{R}$ mIPSCs and the reappearance of mixed GABA $A_{A} R /$ GlyR mIPSCs. Consistent with a relationship between the stimulation of the synthesis of $5 \alpha \mathrm{NS}$ in the spinal cord and the increase of synaptic inhibition in lamina II, we observed that both phenomena were blocked by FIN or PK11195.

The exact link between peripheral inflammation and the upregulation of neurosteroidogenesis remains to be determined, but our results clearly indicate that the PBR plays a fundamental role. The regulation of PBR activity or expression by intracellular signaling pathways is not well understood in the nervous system. An increase in PBR expression has been reported in sensory neurons after nerve injury (Karchewski et al., 2004) and in the spinal cord during inflammation associated with experimental autoimmune encephalomyelitis (Agnello et al., 2000). Peripheral inflammation causes both a central sensitization, caused by the release of glutamate and neuropeptides from primary afferent nociceptors in lamina II (Millan, 1999; Woolf and Salter, 2000 ), and the activation of glial cells in the DH (Watkins et al., 2001). Activated glial cells, in turn, release signaling molecules including proinflammatory cytokines such as
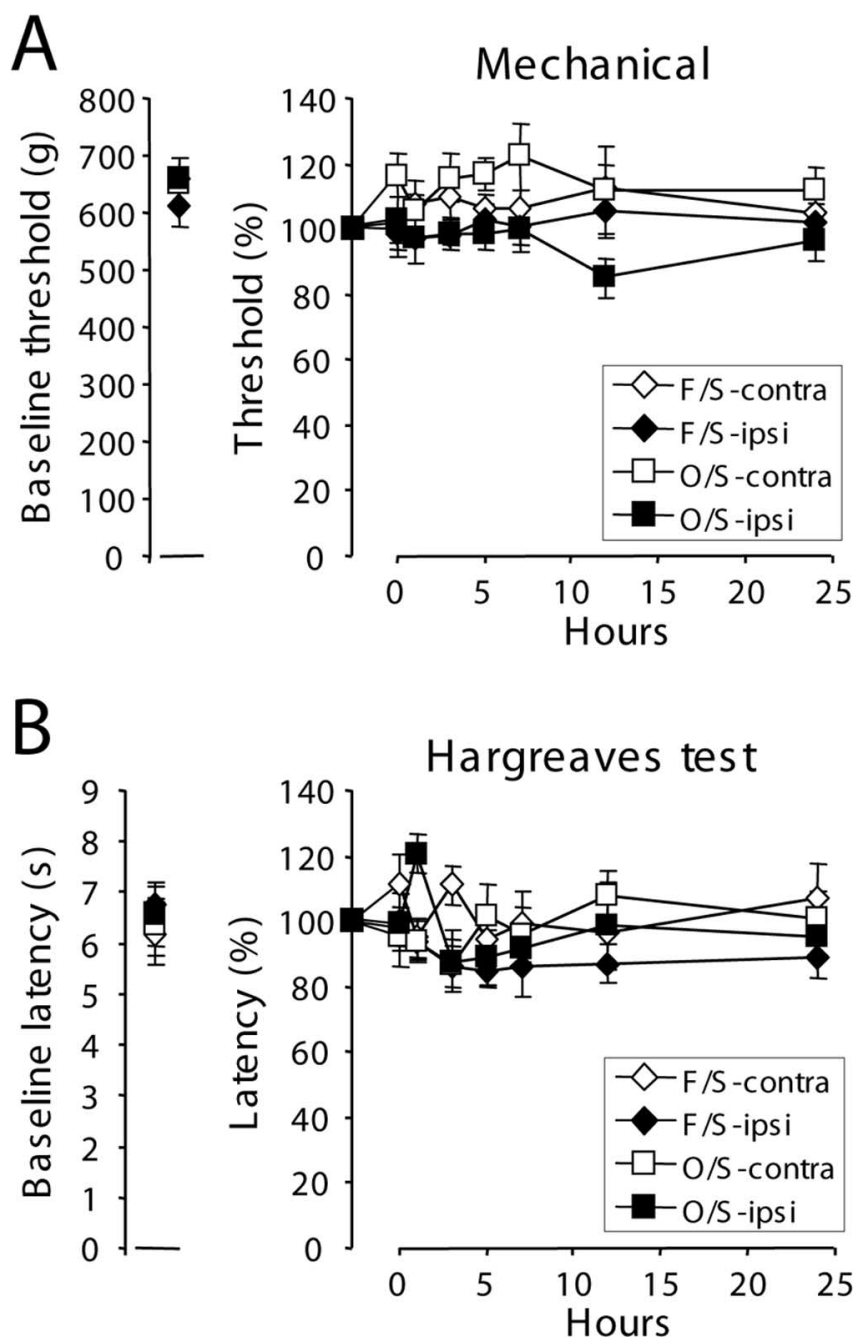

Figure 5. FIN has no effect on nociceptive mechanical and heat thresholds of rats receiving a saline injection in their right hindpaw. $\boldsymbol{A}, \boldsymbol{B}$, Time courses of paw withdrawal thresholds after mechanical $(\boldsymbol{A})$ or thermal heat stimuli ( $\boldsymbol{B}$; Hargreaves' test) in two control groups of animals: oil-saline $(0 / S)$, pretreated with subcutaneous oil injection $(24 \mathrm{~h})$ and injected with saline in the right hindpaw [open and filled squares for contralateral (contra) and ipsilateral (ipsi) paw, respectively], and finasteride-saline (F/S), pretreated with finasteride (30 mg/kg, s.c.) and injected with saline into the hindpaw (open and filled diamonds for contralateral and ipsilateral paw, respectively). The graph on the left indicates the baseline values of mechanical $(\boldsymbol{A})$ and heat $(\boldsymbol{B})$ sensitivity determined for each experimental group before saline injection in the hindpaws. Results are expressed as mean value \pm SEM.

interleukin- $1 \beta$ or interleukin- 6 , which induce the production of prostaglandin $\mathrm{E}_{2}$, leading to thermal and mechanical hyperalgesia associated with inflammatory/neuropathic pain states (Samad et al., 2001; Watkins et al., 2001). Therefore, various signal- 

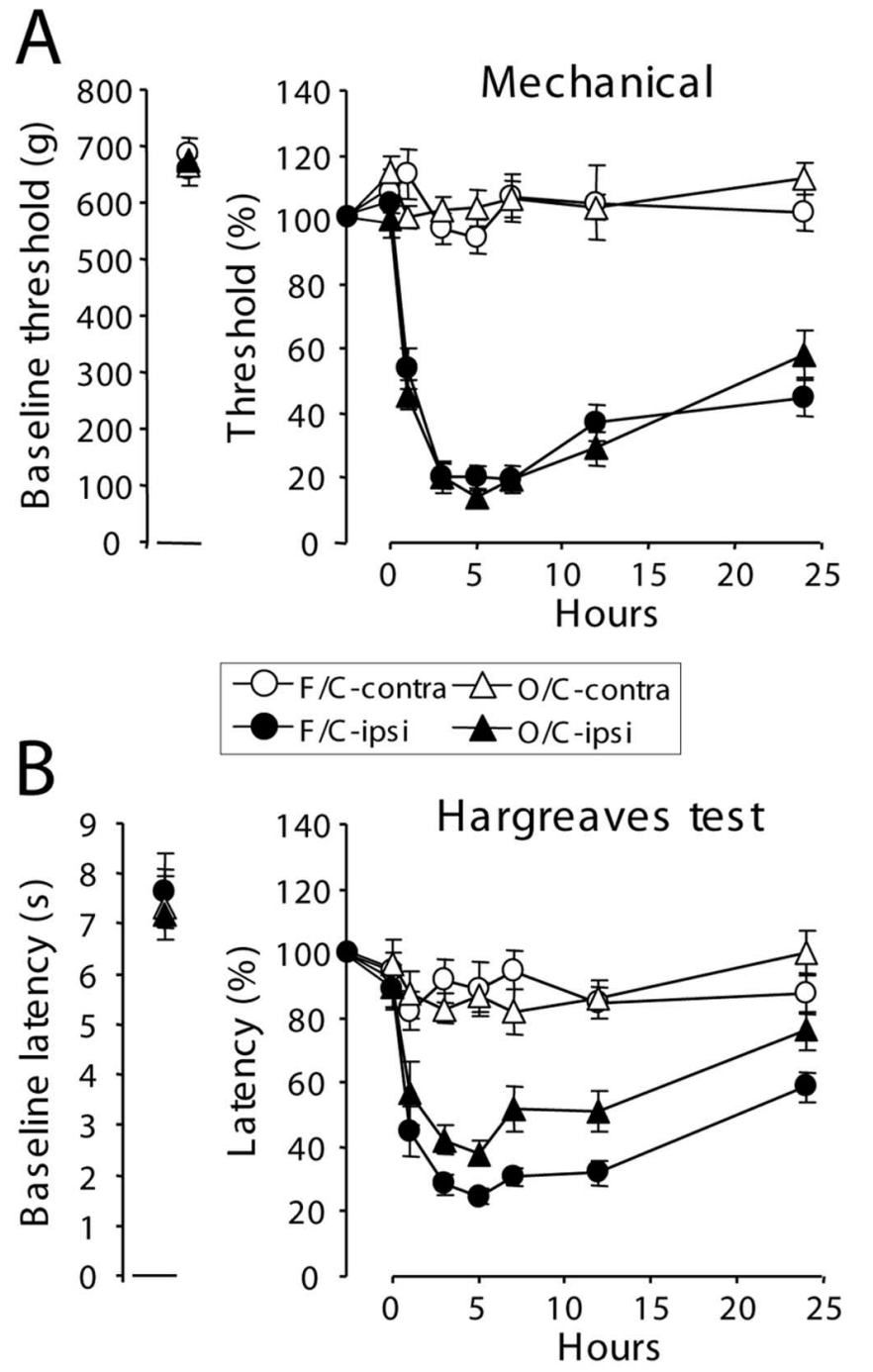

C

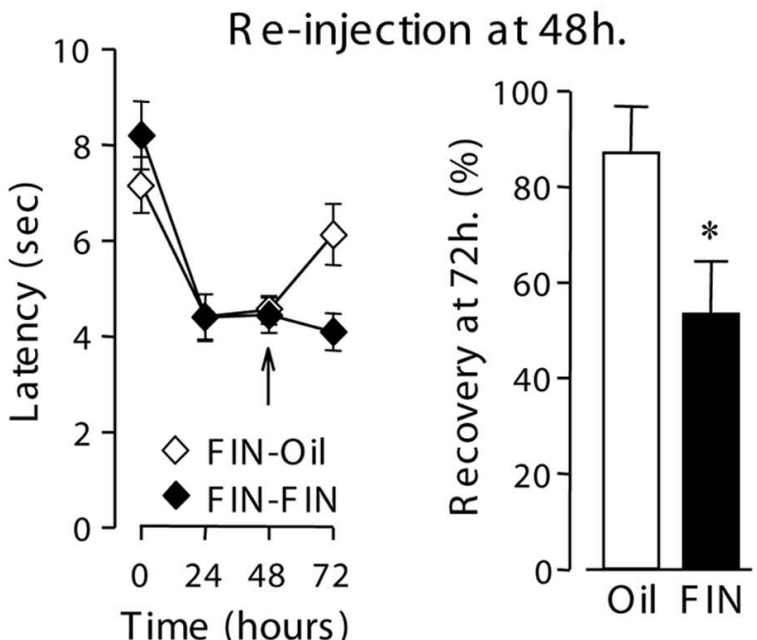

Figure 6. Carrageenan-induced production of $5 \alpha \mathrm{NS}$ reduces thermal but not mechanical hyperalgesia. $\boldsymbol{A}, \boldsymbol{B}$, Time course of paw withdrawal thresholds after mechanical $(\boldsymbol{A})$ or thermal heat stimuli ( $\boldsymbol{B}$; Hargreaves' test) in two carrageenan-injected animal groups: oil-carrageenan $(0 / \mathrm{C})$, pretreated with subcutaneous oil injection ( $24 \mathrm{~h}$ ) and injected with carrageenan $(3 \%)$ in the hindpaw (open and filled triangles for contralateral and ipsilateral paw, respectively), and finasteride - carrageenan $(F / C)$, pretreated with finasteride $(30 \mathrm{mg} / \mathrm{kg}$ ) and injected with carrageenan $(3 \%)$ in the hindpaw (open and filled circles for contralateral and ipsilateral paw, respectively). A pronociceptive effect of finasteride was observed for the ipsilateral hindpaw of $\mathrm{F} / \mathrm{C}$ animals in response to thermal heat stimuli $(\boldsymbol{B})$ but not for mechanical stimuli $(\boldsymbol{A})$. The graph ing molecules released in lamina II by primary afferents, descending supraspinal controls (Millan, 2002), or glial cells are likely to activate intracellular second messenger cascades, which might modulate neurosteroidogenesis.

Our behavioral tests indicated that peripheral inflammation induced a thermal heat hyperalgesia and a mechanical allodynia. When the production of $5 \alpha$ NS was inhibited in vivo by pretreatment of the animals with finasteride before the induction of the inflammation, we observed a significant increase in heat hyperalgesia but no change in mechanical allodynia. Although an increase in the production of $5 \alpha \mathrm{NS}$ in lamina II of the DH could explain most of the results on heat hyperalgesia (see below), we cannot, however, exclude that FIN also acted at the supraspinal site involved in the control of thermal nociception. Nociceptive heat messages involve mainly the activation of unmyelinated C-type primary afferents, which terminate mostly in lamina II of the DH (Light and Perl, 1979a; Light et al., 1979), whereas mechanical noxious stimuli involve the activation of A $\delta$ afferents, which project mainly to lamina I and more deeper laminas (III-V) but only modestly to lamina II (Light and Perl, 1979b). Moreover, in the adult, $\mathrm{A} \beta$ fibers, which are thought to be major mediators of mechanical allodynia (Woolf and Doubell, 1994; Ossipov et al., 1999, 2000), project exclusively to deep laminas (III-VII) but not to laminas I-II (Ralston et al., 1984; Light and Perl, 1979a). Therefore, it appears that an inhibitory mechanism, which would preferentially affect the messages from C-fibers in lamina II, would primarily impact on thermal hyperalgesia, whereas inhibition of mechanical noxious transmission would require an increased inhibition in deeper laminas. Interestingly, an increase in GABAergic tone in the DH has been suggested in rats with chronic inflammatory pain (Castro et al., 1999). This suggests that a selective increase in the inhibition of the $\mathrm{C}$-fiber input to the spinal cord dorsal horn could take place in lamina II, where these fibers terminate. Such a phenomenon could also account for our results. Indeed, the nociceptive heat test used in our study involved rather slow ramp-like stimulation, which has been shown to activate preferentially, if not exclusively, C-fiber nociceptors (Yeomans and Proudfit, 1996; Yeomans et al., 1996; Bian et al., 1998; Ossipov et al., 1999). We show that such C-fibermediated responses were clearly potentiated by FIN, indicating an increased inhibitory tone on C-fiber responses after inflammation resulting from an upregulation of $5 \alpha \mathrm{NS}$. In contrast, $\mathrm{A} \delta /$ $\mathrm{A} \beta$-mediated mechanical responses were unaffected by FIN. This might be explained by a differential regulation of neurosteroidogenesis in different laminas of the spinal cord after peripheral inflammation and/or a differential effect of descending controls on thermal versus mechanical nociceptive pathways (Millan, 2002). The increased production of $5 \alpha \mathrm{NS}$ and the consecutive increase in synaptic inhibition in lamina II also favored the re-

$\leftarrow$

on the left indicates the baseline values of mechanical $(\boldsymbol{A})$ or heat $(\boldsymbol{B})$ sensitivity for each experimental group determined just before carrageenan injection. $\boldsymbol{C}$, Left graph illustrates the effect of a subcutaneous reinjection (arrow) of FIN (FIN-FIN; $30 \mathrm{mg} / \mathrm{kg}$ ) or vehicle (FIN-0il) in F/C animals $48 \mathrm{~h}$ after the induction of peripheral inflammation. Note that FIN-FIN animals (black diamonds) exhibited similar paw-withdrawal latencies at 24,48 , and 72 h, whereas FIN-0il animals (white diamonds) returned progressively to the value observed before inflammation. Right graph illustrates the percentage of recovery of $\mathrm{F} / \mathrm{C}$ animals (with respect to nociceptive heat thresholds measured before carrageenan injection) $72 \mathrm{~h}$ after the induction of peripheral inflammation and after having received oil or FIN at $48 \mathrm{~h}$. The recovery of heat-induced withdrawal responses at $72 \mathrm{~h}$ was only of $\sim 55 \%$ in FIN-FIN animals ( ${ }^{*} p<0.05$ against FIN $\left.-0 \mathrm{il}\right)$, whereas it was complete in the case of FIN-0il animals (i.e., no difference with values measured before carrageenan injection). Results are expressed as mean value \pm SEM. 
covery of noxious heat thresholds toward baseline levels in inflamed animals because this recovery phase was markedly delayed in FIN-treated animals (Fig. 6B). Moreover, when carrageenan-inflamed animals were injected with FIN during the recovery phase (Fig. $6 \mathrm{C}$ ), there was no recovery toward normal heat pain threshold over the next $24 \mathrm{~h}$, whereas vehicle-injected animals completely recovered the threshold values measured before carrageenan injection over the same time period (Fig. 6C).

In conclusion, our results demonstrate for the first time the upregulation of the production of $5 \alpha \mathrm{NS}$ in lamina II of the spinal cord in response to a peripheral painful inflammation. This leads to a potentiation of inhibitory synaptic transmission in lamina II and to a parallel inhibition of thermal heat hyperalgesia, whereas mechanical hyperalgesia or allodynia are unaffected. These results reinforce the idea that nociceptive heat and mechanical messages are processed by separate pathways and modulated by distinct endogenous mechanisms (Bian et al., 1998; Ossipov et al., 1999). Therefore, endogenous $5 \alpha$ NS and their biosynthetic enzymes might represent possible targets for the pharmacological management of thermal hyperalgesia associated with different forms of pain.

\section{References}

Agnello D, Carvelli L, Muzio V, Villa P, Bottazzi B, Polentarutti N, Mennini T, Mantovani A, Ghezzi P (2000) Increased peripheral benzodiazepine binding sites and pentraxin 3 expression in the spinal cord during EAE: relation to inflammatory cytokines and modulation by dexamethasone and rolipram. J Neuroimmunol 109:105-111.

Ahmadi S, Lippross S, Neuhuber WL, Zeilhofer HU (2002) PGE(2) selectively blocks inhibitory glycinergic neurotransmission onto rat superficial dorsal horn neurons. Nat Neurosci 5:34-40.

Araki T, Tohyama M (1992) Region-specific expression of $\mathrm{GABA}_{\mathrm{A}}$ receptor $\alpha 3$ and $\alpha 4$ subunits mRNAs in the rat brain. Brain Res Mol Brain Res 12:293-314.

Baulieu EE, Robel P (1990) Neurosteroids: a new brain function? J Steroid Biochem Mol Biol 37:395-403.

Bian D, Ossipov MH, Zhong C, Malan Jr TP, Porreca F (1998) Tactile allodynia, but not thermal hyperalgesia, of the hindlimbs is blocked by spinal transection in rats with nerve injury. Neurosci Lett 241:79-82.

Bohlhalter S, Weinmann O, Mohler H, Fritschy JM (1996) Laminar compartmentalization of $\mathrm{GABA}_{\mathrm{A}}$-receptor subtypes in the spinal cord: an immunohistochemical study. J Neurosci 16:283-297.

Brussaard AB, Koksma JJ (2003) Conditional regulation of neurosteroid sensitivity of GABA $A_{A}$ receptors. Ann NY Acad Sci 1007:29-36.

Casellas P, Galiegue S, Basile AS (2002) Peripheral benzodiazepine receptors and mitochondrial function. Neurochem Int 40:475-486.

Castro AR, Bowery N, Castro-Lopes JM (1999) Baclofen and midazolam alter c-fos induction by peripheral noxious or innocuous stimulation in the spinal cord of normal and monoarthritic rats. Neuropharmacology 38:1775-1788.

Cherubini E, Conti F (2001) Generating diversity at GABAergic synapses. Trends Neurosci 24:155-162.

Chéry N, De Koninck Y (1999) Junctional versus extrajunctional glycine and $\mathrm{GABA}_{\mathrm{A}}$ receptor-mediated IPSCs in identified lamina I neurons of the adult rat spinal cord. J Neurosci 19:7342-7355.

Coirini H, Gouezou M, Liere P, Delespierre B, Pianos A, Eychenne B, Schumacher M, Guennoun R (2002) 3 $\beta$-Hydroxysteroid dehydrogenase expression in rat spinal cord. Neuroscience 113:883-891.

Cooper EJ, Johnston GA, Edwards FA (1999) Effects of a naturally occurring neurosteroid on $\mathrm{GABA}_{\mathrm{A}}$ IPSCs during development in rat hippocampal or cerebellar slices. J Physiol (Lond) 521:437-449.

Grudt TJ, Henderson G (1998) Glycine and GABA ${ }_{\mathrm{A}}$ receptor-mediated synaptic transmission in rat substantia gelatinosa: inhibition by $\mu$-opioid and $\mathrm{GABA}_{\mathrm{B}}$ agonists. J Physiol (Lond) 507:473-483.

Hargreaves K, Dubner R, Brown F, Flores C, Joris J (1988) A new and sensitive method for measuring thermal nociception in cutaneous hyperalgesia. Pain 32:77-88.

Harvey RJ, Depner UB, Wassle H, Ahmadi S, Heindl C, Reinold H, Smart TG, Harvey K, Schutz B, Abo-Salem OM, Zimmer A, Poisbeau P, Welzl H,
Wolfer DP, Betz H, Zeilhofer HU, Muller U (2004) GlyR $\alpha 3$ : an essential target for spinal PGE2-mediated inflammatory pain sensitization. Science 304:884-887.

Ishikawa T, Marsala M, Sakabe T, Yaksh TL (2000) Characterization of spinal amino acid release and touch-evoked allodynia produced by spinal glycine or $\mathrm{GABA}_{\mathrm{A}}$ receptor antagonist. Neuroscience 95:781-786.

Jones-Davis DM, Macdonald RL (2003) $\mathrm{GABA}_{\mathrm{A}}$ receptor function and pharmacology in epilepsy and status epilepticus. Curr Opin Pharmacol 3:12-18.

Karchewski LA, Bloechlinger S, Woolf CJ (2004) Axonal injury-dependent induction of the peripheral benzodiazepine receptor in small-diameter adult rat primary sensory neurons. Eur J Neurosci 20:671-683.

Keller AF, Coull JA, Chery N, Poisbeau P, De Koninck Y (2001) Regionspecific developmental specialization of GABA-glycine cosynapses in laminas I-II of the rat spinal dorsal horn. J Neurosci 21:7871-7880.

Keller AF, Breton JD, Schlichter R, Poisbeau P (2004) Production of $5 \alpha$ reduced neurosteroids is developmentally regulated and shapes $\mathrm{GABA}_{\mathrm{A}}$ miniature IPSCs in lamina II of the spinal cord. J Neurosci 24:907-915.

Koksma JJ, van Kesteren RE, Rosahl TW, Zwart R, Smit AB, Luddens H, Brussaard $A B$ (2003) Oxytocin regulates neurosteroid modulation of $\mathrm{GABA}_{\mathrm{A}}$ receptors in supraoptic nucleus around parturition. J Neurosci 23:788-797.

Kondo E, Kiyama H, Araki T, Shida T, Ueda Y, Tohyama M (1994) Coexpression of $\mathrm{GABA}_{\mathrm{A}}$ receptor $\gamma 1$ and $\gamma 2$ subunits in the rat trigeminal ganglion. Brain Res Mol Brain Res 21:363-367.

Lambert JJ, Belelli D, Peden DR, Vardy AW, Peters JA (2003) Neurosteroid modulation of $\mathrm{GABA}_{\mathrm{A}}$ receptors. Prog Neurobiol 71:67-80.

Leroy C, Poisbeau P, Keller AF, Nehlig A (2004) Pharmacological plasticity of $\mathrm{GABA}_{\mathrm{A}}$ receptors at dentate gyrus synapses in a rat model of temporal lobe epilepsy. J Physiol (Lond) 557:473-487.

Light AR, Perl ER (1979a) Reexamination of the dorsal root projection to the spinal dorsal horn including observations on the differential termination of coarse and fine fibers. J Comp Neurol 186:117-131.

Light AR, Perl ER (1979b) Spinal termination of functionally identified primary afferent neurons with slowly conducting myelinated fibers. J Comp Neurol 186:133-150.

Light AR, Trevino DL, Perl ER (1979) Morphological features of functionally defined neurons in the marginal zone and substantia gelatinosa of the spinal dorsal horn. J Comp Neurol 186:151-171.

Millan MJ (1999) The induction of pain: an integrative review. Prog Neurobiol 57:1-164.

Millan MJ (2002) Descending control of pain. Prog Neurobiol 66:355-474.

Mtchedlishvili Z, Bertram EH, Kapur J (2001) Diminished allopregnanolone enhancement of $\mathrm{GABA}_{\mathrm{A}}$ receptor currents in a rat model of chronic temporal lobe epilepsy. J Physiol (Lond) 537:453-465.

Ossipov MH, Bian D, Malan Jr TP, Lai J, Porreca F (1999) Lack of involvement of capsaicin-sensitive primary afferents in nerve-ligation injury induced tactile allodynia in rats. Pain 79:127-133.

Ossipov MH, Lai J, Malan Jr TP, Porreca F (2000) Spinal and supraspinal mechanisms of neuropathic pain. Ann NY Acad Sci 909:12-24.

Patte-Mensah C, Kappes V, Freund-Mercier MJ, Tsutsui K, Mensah-Nyagan AG (2003) Cellular distribution and bioactivity of the key steroidogenic enzyme, cytochrome P450side chain cleavage, in sensory neural pathways. J Neurochem 86:1233-1246.

Patte-Mensah C, Penning TM, Mensah-Nyagan AG (2004) Anatomical and cellular localization of neuroactive $5 \alpha / 3 \alpha$-reduced steroid-synthesizing enzymes in the spinal cord. J Comp Neurol 477:286-299.

Poisbeau P, Feltz P, Schlichter R (1997) Modulation of $\mathrm{GABA}_{\mathrm{A}}$ receptormediated IPSCs by neuroactive steroids in a rat hypothalamohypophyseal coculture model. J Physiol (Lond) 500:475-485.

Poletti A, Coscarella A, Negri-Cesi P, Colciago A, Celotti F, Martini L (1998) $5 \alpha$-Reductase isozymes in the central nervous system. Steroids 63:246-251.

Ralston III HJ, Light AR, Ralston DD, Perl ER (1984) Morphology and synaptic relationships of physiologically identified low-threshold dorsal root axons stained with intra-axonal horseradish peroxidase in the cat and monkey. J Neurophysiol 51:777-792.

Samad TA, Moore KA, Sapirstein A, Billet S, Allchorne A, Poole S, Bonventre JV, Woolf CJ (2001) Interleukin-1 $\beta$-mediated induction of Cox- 2 in the CNS contributes to inflammatory pain hypersensitivity. Nature 410:471-475. 
Sivilotti L, Woolf CJ (1994) The contribution of $\mathrm{GABA}_{\mathrm{A}}$ and glycine receptors to central sensitization: disinhibition and touch-evoked allodynia in the spinal cord. J Neurophysiol 72:169-179.

Smith SS, Gong QH, Hsu FC, Markowitz RS, ffrench-Mullen JM, Li X (1998) $\mathrm{GABA}_{\mathrm{A}}$ receptor $\alpha 4$ subunit suppression prevents withdrawal properties of an endogenous steroid. Nature 392:926-930.

Stoner E (1990) The clinical development of a $5 \alpha$-reductase inhibitor, finasteride. J Steroid Biochem Mol Biol 37:375-378.

Treiman DM (2001) GABAergic mechanisms in epilepsy. Epilepsia 42 [Suppl 3]:8-12.

Vinegar R, Truax JF, Selph JL, Johnston PR, Venable AL, McKenzie KK (1987) Pathway to carrageenan-induced inflammation in the hind limb of the rat. Fed Proc 46:118-126.
Watkins LR, Milligan ED, Maier SF (2001) Spinal cord glia: new players in pain. Pain 93:201-205.

Woolf CJ, Doubell TP (1994) The pathophysiology of chronic pain: in creased sensitivity to low threshold A $\beta$-fibre inputs. Curr Opin Neurobiol 4:525-534.

Woolf CJ, Salter MW (2000) Neuronal plasticity: increasing the gain in pain. Science 288:1765-1769.

Yeomans DC, Proudfit HK (1996) Nociceptive responses to high and low rates of noxious cutaneous heating are mediated by different nociceptors in the rat: electrophysiological evidence. Pain 68:141-150.

Yeomans DC, Pirec V, Proudfit HK (1996) Nociceptive responses to high and low rates of noxious cutaneous heating are mediated by different nociceptors in the rat: behavioral evidence. Pain 68:133-140. 